\title{
USO DE MODELOS DIGITAIS DE ELEVAÇÃO PARA MAPEAMENTO DE VARIÁVEIS MORFOMÉTICAS DO RELEVO NA BACIA HIDROGRÁFICA DO RIO SÃO JOÃO
}

\author{
Use of digital elevation models for mapping morphometric relief in the basin of the \\ river São João
}

\author{
Vinicius da Silva Seabra \\ Doutor, Professor da Faculdade de Formação de Professores da Universidade do Estado do \\ Rio de Janeiro - UERJ/FFP \\ vinigeobr@gmail.com
}

Artigo recebido em 15/11/2012 e aceito para publicação em 28/12/2012

RESUMO As análises morfométricas do terreno são importantes ferramentas para a gestão e ordenamento do território, sobretudo para ações voltadas para a recuperação e preservação, em áreas ambientalmente importantes. A bacia hidrográfica do rio São João (BHRSJ) é uma destas importantes áreas, pois nela podemos encontrar uma grande variedade de ambientes e ecossistemas, o que resulta em uma grande diversidade de habitats e, por consequência, um grande endemismo de espécies. Sendo assim, este artigo teve o objetivo de propor uma adaptação da metodologia do IPT (1981) para o mapeamento morfométrico do relevo na bacia hidrográfica do rio São João, no estado do Rio de Janeiro. As variáveis utilizadas no modelo foram obtidas a partir do modelo ASTER MDE, e da interpretação de uma imagem SPOT 5. Os resultados desta pesquisa identificaram diferentes feições na BHRSJ, tais como: Montanhas, morrotes, morros, colinas e planícies. Estes resultados foram considerados muito compatíveis com observações obtidas em campo, para toda a área mapeada. Palavras chave: Mapeamento geomorfológico, MDE ASTER, análise morfométrica do terreno.

ABSTRACT The morphometric analysis of the terrain are important tools for the management and planning, especially for actions for the recovery and preservation in environmentally important areas. The watershed of the St. John River (BHRSJ) is one of these important areas, because it can find a wide range of environments and ecosystems, resulting in a great diversity of habitats and therefore a great endemism of species. Thus, this paper aimed to propose an adaptation of the methodology of IPT (1981) for mapping morphometric relief in the basin of the river St. John, in the state of Rio de Janeiro. The variables used in the model were obtained from the ASTER DEM model, and from the interpretation of a SPOT 5 (HRG) image. The results of this study identified different features in BHRSJ such as: Mountains, morrotes, hills and plains. These results were considered very compatible with observations obtained in the field for the entire mapped area.

Keywords: Geomorphological mapping, ASTER DEM, morphometric analysis of the terrain 


\section{INTRODUÇÃO}

As análises relacionadas à gênese e formas de relevo permitem a interpretação dos processos, fenômenos e interações existentes entre os diversos elementos abióticos que compõem a paisagem. Os estudos geomorfológicos dos terrenos possibilitam a dedução da tipologia e intensidade dos processos erosivos e deposicionais, a distribuição, textura e composição dos solos e ainda a aptidão para o seu uso. Assim como os fatores do clima, a geomorfologia serve como uma importante barreira para o estabelecimento de determinadas espécies, e também cria condições favoráveis ou desfavoráveis às atividades humanas.

De acordo com as formas do relevo, poderemos ter a formação de áreas onde o sombreamento cria condições melhores para o estabelecimento de determinadas espécies vegetacionais, ou o inverso, onde as formas do relevo expõem algumas áreas a uma maior insolação. Estas análises também respondem pelo estabelecimento de áreas onde ocorre acúmulo de água e nutrientes, ou o contrario, pela formação de áreas onde há dispersão de água, sedimentos e nutrientes.

Os atuais avanços geotecnológicos têm tornado cada vez mais eficientes as análises ambientais. O emprego destas tecnologias permite a aquisição de informações em diferentes escalas, a um custo mais reduzido. A disponibilização gratuita de

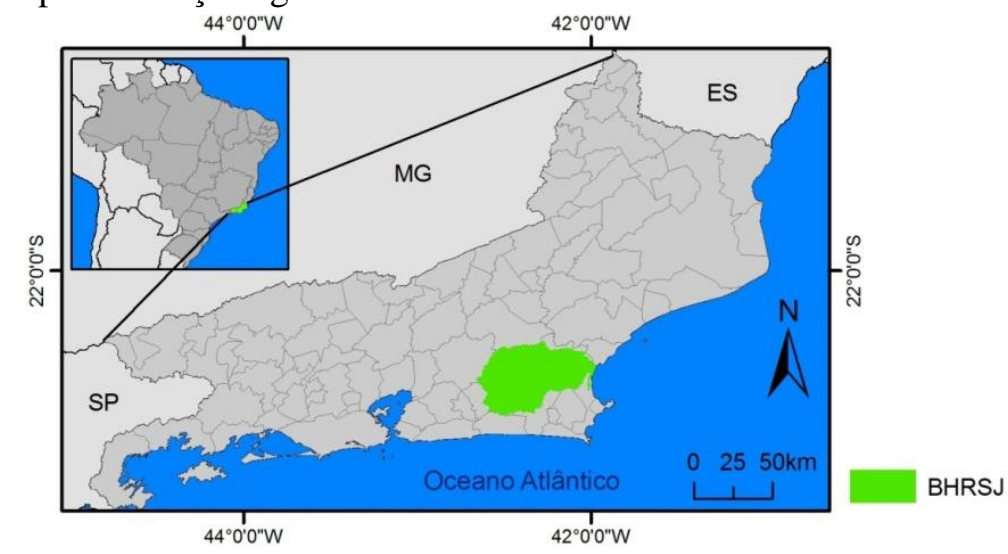

Figura 1. Localização da bacia hidrográfica do rio São João (BHRSJ). Projeção Cilíndrica Equiretângular. SIRGAS 2000. dados hipsométricos através de modelos digitais de elevação permite ainda a elaboração de mapeamentos de áreas que, sem estes insumos, dificilmente poderiam ser representadas.

O presente trabalho teve como objetivo o mapeamento dos sistemas de relevo da bacia hidrográfica do rio São João (BHRSJ) em escala de 1:100.000. A metodologia empregada foi elaborada a partir de adaptações dos métodos aplicados pelo IPT (1981) no Mapeamento Geomorfológico do Estado de São Paulo, e a obtenção das variáveis necessárias ao modelo de classificação da morfologia do relevo se deu a partir da manipulação de um recorte do MDE ASTER e uma de imagem SPOT 5 ((HRG) de 2006.

A escolha da BHRSJ como área de estudos deve-se a grande heterogeneidade de formações geomorfológicas existentes no recorte espacial analisado, já que em toda região são encontrados os mais variados tipos de formações, com paisagens montanhosas e escarpadas, relevos de morros, morrotes, colinas, planícies fluviais ou flúvio-lagunares e planícies costeiras.

A BHRSJ localiza-se dentro do contexto da Mata Atlântica, situada entre o corredor da Serra do Mar e o litoral atlântico. Esta bacia posiciona-se a oeste da Bacia Hidrográfica da Baia da Guanabara, estando quase que em sua totalidade na Região das Baixadas Litorâneas do Estado do Rio de Janeiro (fig. 1). 
Segundo o Consórcio Intermunicipal Lagos São João (CILSJ, 2007) a BHRSJ estende-se por $63 \mathrm{~km}$ no sentido leste-oeste e por $43 \mathrm{~km}$ no sentido norte-sul, possuindo uma área total de $2.160 \mathrm{~km}^{2}$. A Bacia é limitada em sua porção Norte e Noroeste pelo conjunto de montanhas e escarpas pertencentes à Serra do Mar, ao Sudoeste é limitada por maciços costeiros e interiores situados nos limites dos municípios de Saquarema e Rio Bonito, e ao sul por domínios colinosos cujas amplitudes predominantes não ultrapassam a cota de $100 \mathrm{~m}$ e as declividades geralmente oscilam entre $5 \%$ e $15 \%$.

\section{METODOLOGIA}

Os cálculos das variáveis geomorfológicas foram elaborados a partir do uso dos dados disponibilizados gratuitamente pelo ASTER GDEM (Advance Space Borne Thermal Emission and Reflection Radiometer - Global Digital Elevation Model), através do Earth Remote Sensing Data Analysis Center (ERSDAC) do Japão, em conjunto com a Land Processes Distributed Active Archive Center (LP DAAC) da NASA. Estes dados dão conta da representação de toda a superfície terrestre a partir de modelos digitais de elevação (Digital Elevation Model) gerados pelo instrumento imageador ASTER, que se encontra a bordo do satélite TERRA lançado em 19 de dezembro de 1999, pela NASA, fazendo parte do projeto Earth Observing System (EOS).

O ASTER é o instrumento de melhor resolução espacial do satélite TERRA, sendo constituído por 3 diferentes subsistemas: VNIR (Visible and Near Infrared); SWIR (Short Wave Infrared); e o TIR (Thermal Infrared), num total de 14 bandas espectrais, cobrindo uma área de 60 x $60 \mathrm{Km}$, com possibilidade de revisita em 16 dias. O MDE ASTER é gerado a partir dos dados das bandas $3 \mathrm{~N}$ e $3 \mathrm{~B}$ do subsistema VNIR. Estas bandas adquirem dados na faixa do infravermelho próximo $(0,78$ a $0,86 \mu \mathrm{m})$.

Os dados de elevação foram disponibilizados com resolução de 30 x 30 metros, o que pode ser considerado uma vantagem se comparados com os dados do SRTM (Shuttle Radar Topography Mission), que também são oferecidos gratuitamente, mas em resolução de 90 x 90 metros. Barros (2006) destaca ainda que a facilidade de manuseio dos modelos ASTER pode ser considerada uma importante vantagem para o usuário, e classifica estes modelos como adequados para a classe C, em escala de 1:50.000, no Padrão de Exatidão Cartográfica (PEC C). Isto viabiliza o uso destes modelos nos mapeamentos temáticos, nas escalas desejadas (1:100.000), para este trabalho.

Para a Bacia do Rio São João utilizouse dois recortes dos modelos ASTER (S23W43 e S23W42) para representação de toda a área de interesse. Estes recortes foram então unidos em um único mosaico e posteriormente recortadas para a área da bacia. A partir da construção do MDE ASTER foi possível elaborar o mapa hipsométrico (fig. 2), de declividade do relevo, de amplitude do relevo, forma do terreno, além de possibilitar a construção de imagens sombreadas e de radiação solar. A leitura do mapa hipsométrico confirma a BHRSJ como uma bacia que possui grandes planícies fluviais, delimitadas ao norte, noroeste e sudoeste por grandes serras e maciços, e ao sul e sudeste por colinas de menor altitude. 


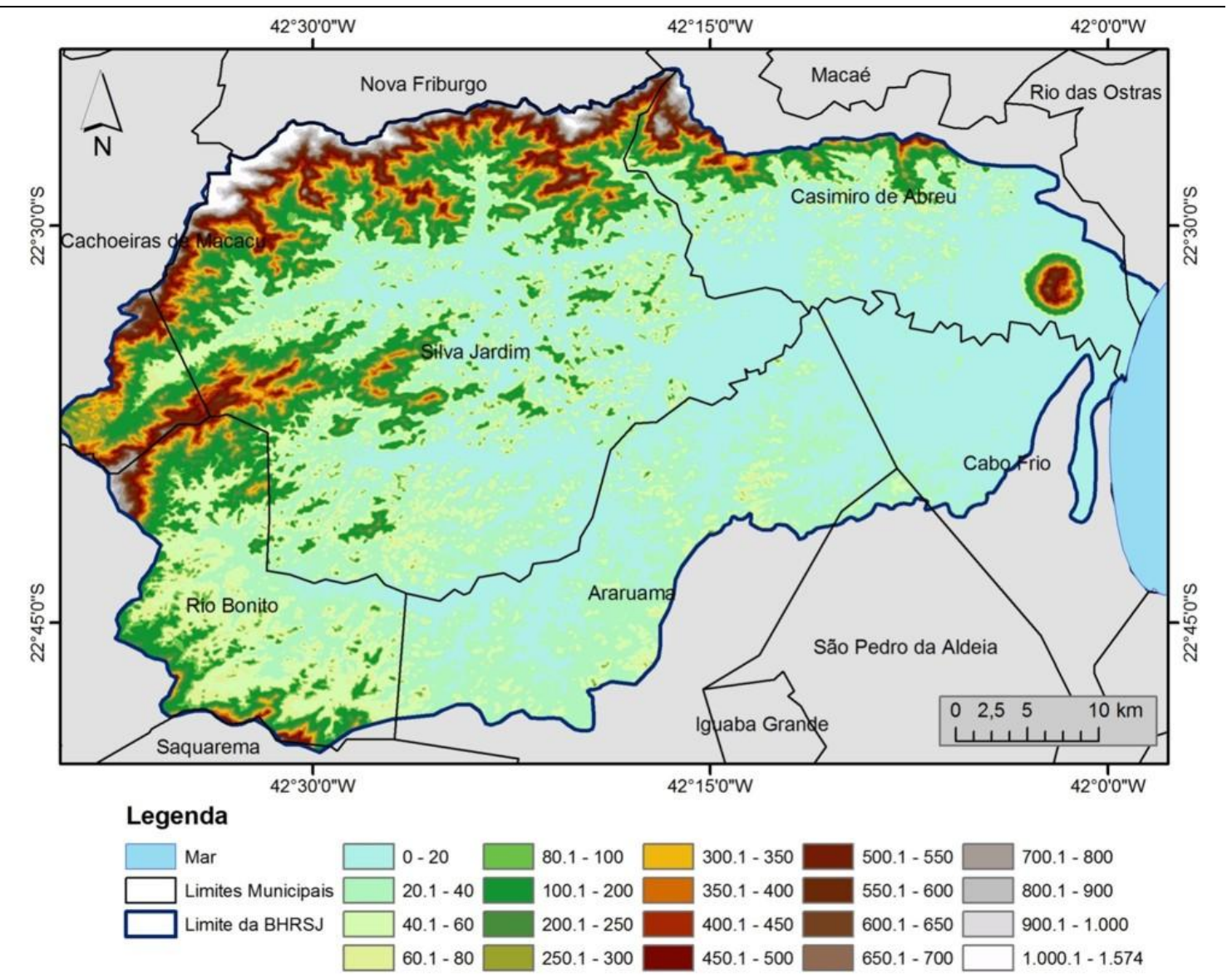

Figura 2. Mapa Hipsométrico. Projeção Cilíndrica Equiretângular. SIRGAS 2000.

\section{CÁlCULO DE DECLIVIDADE DA BHRSJ}

Declividade é a relação entre a diferença de altura entre dois pontos e a distância horizontal entre esses pontos. Portanto, pode-se afirmar que a declividade é o grau de inclinação de um terreno em relação à linha do horizonte, podendo ser expressa também em percentagem, medida pela tangente do ângulo de inclinação multiplicada por 100. Este tema permite inferir sobre as formas da paisagem, erosão, potencialidades de uso agrícola, restrições para a ocupação, manejos e práticas conservacionistas e ainda contribuir na delimitação de áreas de proteção permanente (APP).

As áreas que apresentam altos valores de declividade criam sérias dificuldades ao estabelecimento de diversas atividades humanas, reduzindo com isso as pressões antrópicas existentes sobre os ecossistemas ali presentes, tornando mais altos os valores de favorabilidade à recuperação ambiental nestas áreas. Já nas áreas planas, ou seja, com baixos valores de declividade, as facilidades de acesso e de estabelecimento de atividades antrópicas aumentam as pressões sobre os fragmentos existentes, reduzindo assim as chances de recuperação. No entanto, nas áreas com altos valores de declividade, os processos erosivos são mais significativos e acarretam em dificuldades para o acúmulo de água e nutrientes, criando desta forma, do ponto de vista natural, uma situação desfavorável à recuperação de áreas degradadas.

No mapa de declividade da bacia (fig.3), podemos observar mais uma vez a presença das planícies fluviais (declividade $0-5 \%$ ), com grande destaque para as planícies dos rios São João, Capivari e Bacaxá. Podemos também observar as baixas declividades $(0-5 \%)$ das planícies costeiras, localizadas na foz do Rio São 
João. Além disso, cabe destacar as diferenças de declividade encontradas nas porções norte e noroeste (Serra do Mar), na porção Sudoeste (Maciços Costeiros) e na porção Sul e Sudeste (Relevo de Colinas). Na Região da Serra do Mar observamos um predomínio de um relevo com declividades maiores que $15 \%$, sendo que nas áreas mais próximas ao divisor esta declividade predominante sobe para acima de $45 \%$. Na área dos maciços costeiros, observamos um predomínio de áreas com declividades entre $5-15 \%$, sendo que este predomínio muda para declividades entre $15-45 \%$, e até maiores que $45 \%$, na medida em que nos aproximamos dos divisores. Já na área colinosa, percebemos que a declividade predominante não ultrapassa os valores de $15 \%$, nem mesmo em seus divisores.

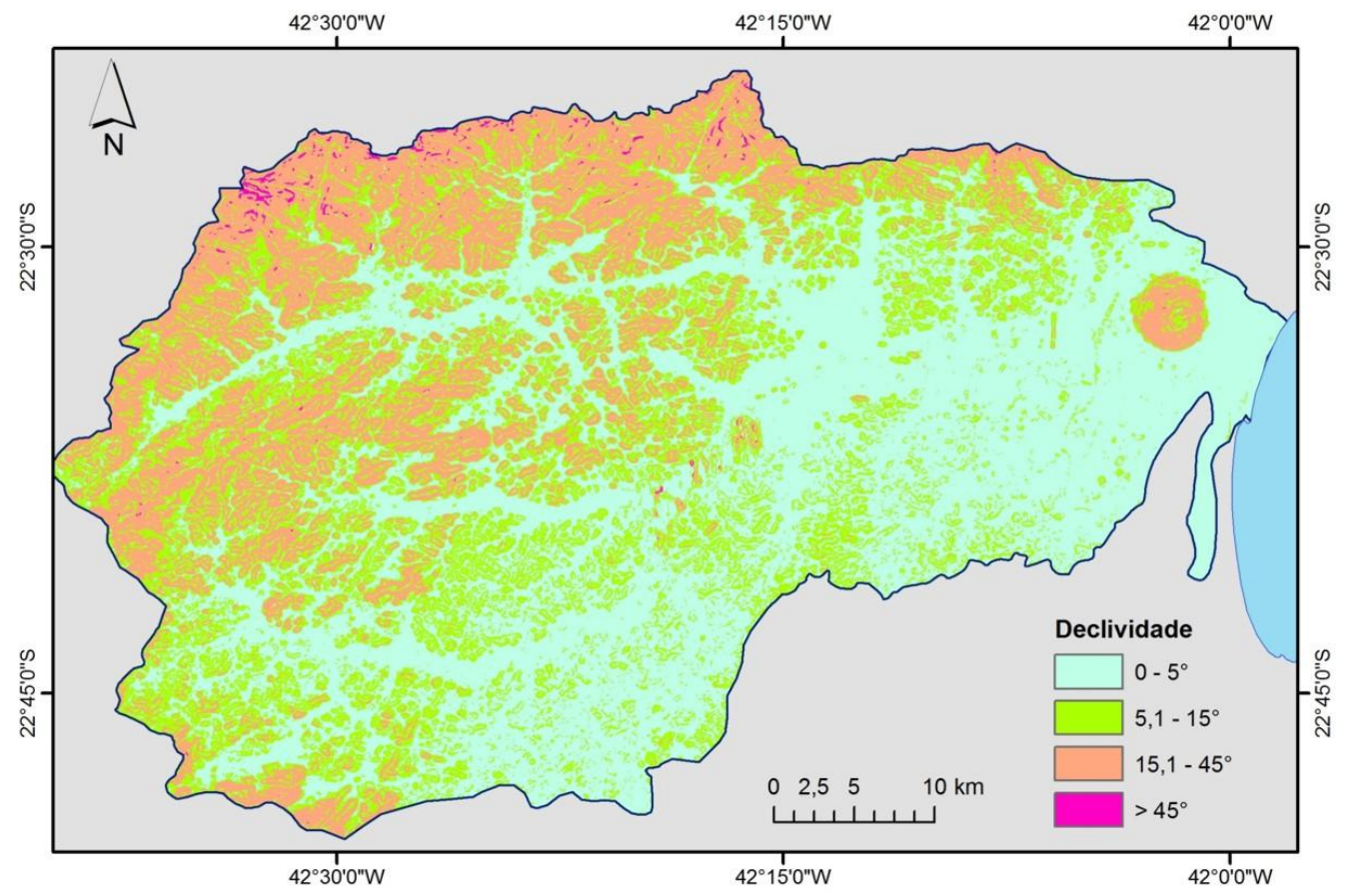

Figura 3. Mapa de Declividade na BHRSJ. Projeção Cilíndrica Equiretângular. Sirgas 2000.

\section{DELIMITAÇÃO DAS BACIAS DE DRENAGEM DE $3^{\text {a }}$ ORDEM}

Foram delimitadas as bacias de drenagem de terceira ordem, e as bacias de drenagem dos rios de menor ordem que são afluentes dos rios principais (fig.4). A delimitação destas bacias foi efetuada de forma semiautomática (função watershed delineation e edição vetorial) $e$ os dados utilizados para esta delimitação foram a hidrografia do IBGE (1:100.000) e o MDE ASTER. O objetivo de se limitar estas áreas era o de encontrar os níveis de base locais, para posterior mapeamento das amplitudes locais. Ao todo foram delimitadas 117 bacias, sendo que 35 localizadas no Alto São João (acima da represa de Juturnaíba), 28 no baixo São João (abaixo da represa de Juturnaíba), 19 bacias de rios afluentes do Rio Capivari, e 35 bacias de rios afluentes do rio Bacaxá. No banco de dados as bacias herdaram o nome de seus principais rios, e ainda carregaram informações referentes à sua bacia principal (alto São João, baixo São João, Capivari e Bacaxá). 


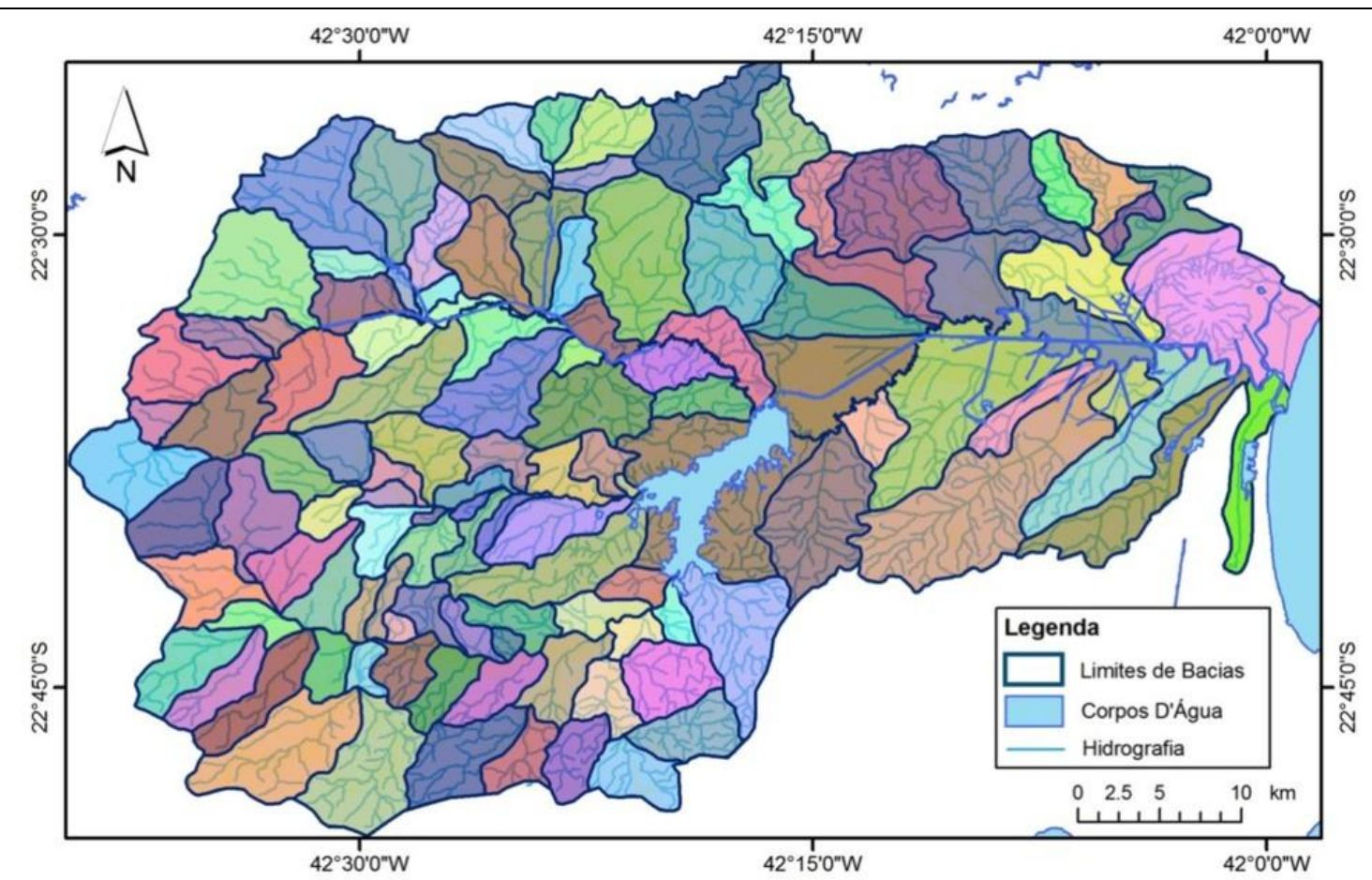

Figura 4. Limites de Bacias na BHRSJ. Projeção Cilíndrica Equiretângular. Sirgas 2000.

\section{CÁlCULO DE AMPLITUDE DO RELEVO DA BHRSJ}

Como mencionado anteriormente, com o auxílio do MDE Aster e de dados topográficos do IBGE (1:50.000), foram traçadas as bacias hidrográficas contribuintes do Rio São João, considerando preferencialmente os limites das bacias de terceira ordem e, em seguida, dos rios contribuintes para os rios principais. Para cada uma destas bacias foram calculados os respectivos níveis de base, que foram então definidos a partir da confluência de rios de $3^{\circ}$ ordem, ou da cota altimétrica da foz dos rios de menor ordem. Com estes limites hidrográficos e com os valores de altitude absoluta, tornou-se possível o cálculo do nível de base para cada sub-bacia e posteriormente o cálculo da amplitude do relevo em cada ponto (fig.5).

Devemos ressaltar que a amplitude do relevo refere-se à diferença entre a altitude de um ponto e a altitude do nível de base local. A amplitude relativa de um relevo é dada pelas alturas ou cotas relativas, que não devem ser confundidas com a altitude absoluta, que é tomada em relação ao nível do mar ou superfície de referência (GUERRA \& GUERRA, 1997).

Os maiores valores de amplitude de relevo (superior a $1000 \mathrm{~m}$ ) representam menos que $1 \%$ da área total da bacia $\mathrm{e}$ foram encontrados em sua porção noroeste (Serra do Mar), em áreas próximas às cabeceiras do rio Pirineus, localizando-se, portanto, nos limites dos municípios de Silva Jardim, Cachoeira de Macacú e Nova Friburgo. Nesta área temos o Pico do Faraó, que é o ponto culminante da bacia com $1.719 \mathrm{~m}$ de altitude. Como podemos observar no mapa, existe o predomínio de áreas com amplitudes inferiores a 40m, seguido da presença de amplitudes intermediárias, onde os valores encontramse entre 300 e $1000 \mathrm{~m}$ (fig. 6). 


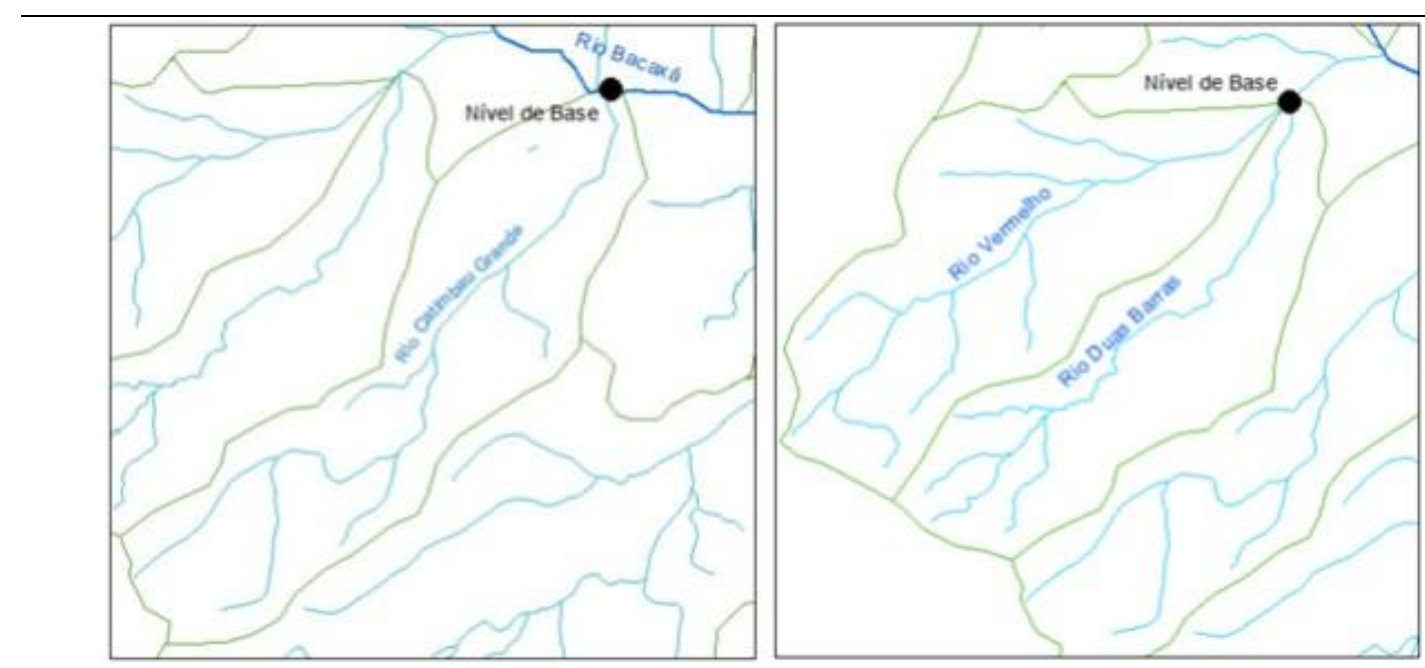

Figura 5. Definição dos Níveis de Base

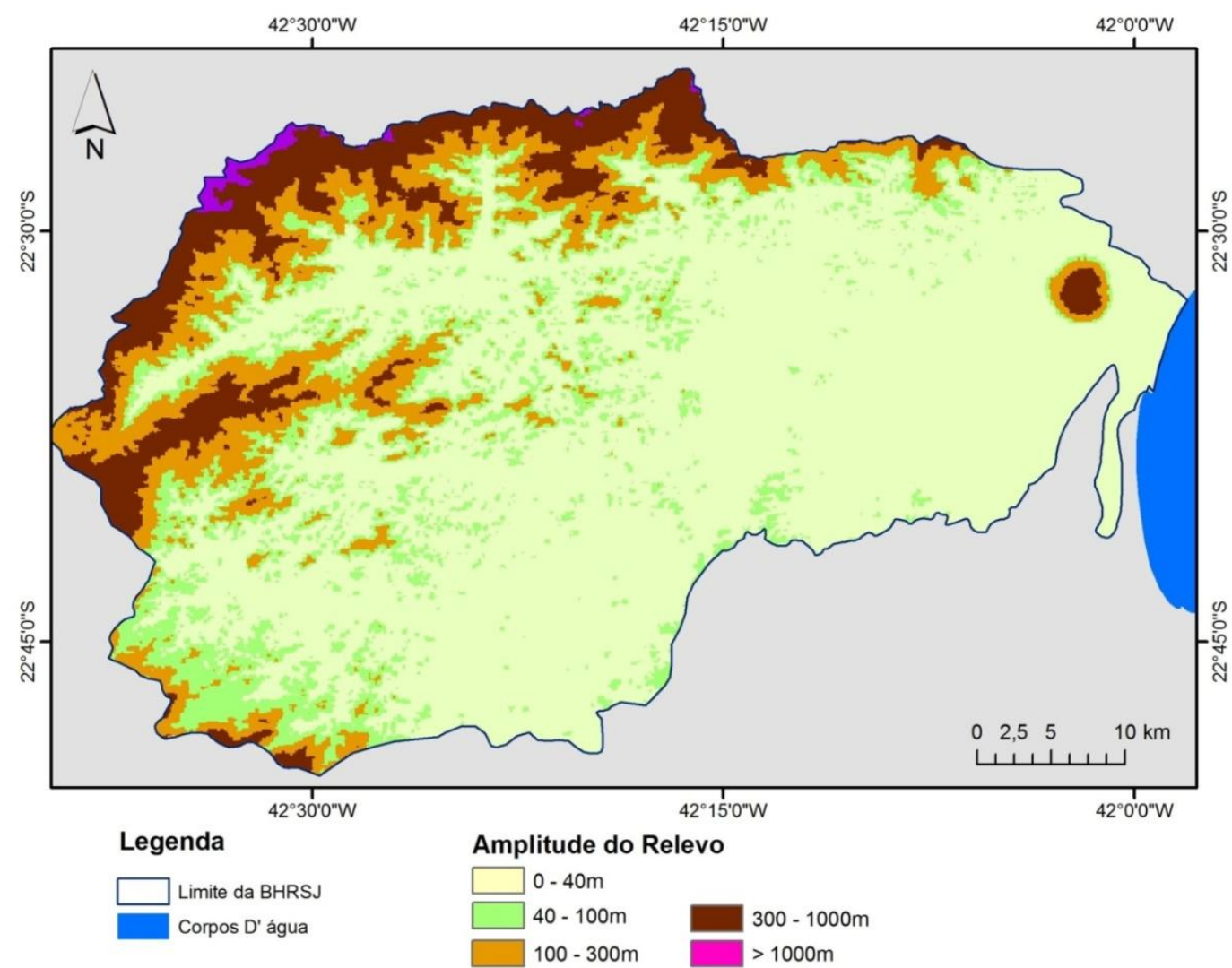

Figura 6. Mapa de Amplitude do Relevo na BHRSJ. Projeção Cilíndrica Equiretângular. Sirgas 2000.

MAPA DE DOMÍNIOS

\section{GEOMORFOLÓGICOS DA BHRSJ}

Os procedimentos adotados para a identificação dos domínios geomorfológicos na BHRSJ foram construídos a partir de adaptações da metodologia empregada pelo IPT (Instituto de Pesquisas Tecnológicas), que em 1981 desenvolveu o Mapa Geomorfológico do Estado de São Paulo (tab. 1). Esta metodologia obteve resultados bem satisfatórios para o entendimento do relevo no Estado e São Paulo, fazendo com que Florenzano (2008), Pires Neto (1992), Florenzano \& Csordas (1993), desenvolvessem mapeamentos geomorfológicos em diferentes regiões do estado de São Paulo aplicando adaptações desta mesma metodologia. Os principais critérios adotados nestes trabalhos são o de 
declividade dominante das vertentes e amplitude do relevo.

Tabela 1: Classes de Sistemas de Relevo para o Estado de São Paulo

\begin{tabular}{l|c|c}
\multicolumn{1}{c|}{ Sistemas de Relevo } & Declividade & Amplitude do Relevo \\
\hline Relevo Colinoso & $0 \%$ a $15 \%$ & $<100 \mathrm{~m}$ \\
\hline Morros com Vertentes Suavizadas & $0 \%$ a $15 \%$ & De $100 \mathrm{~m}$ a $300 \mathrm{~m}$ \\
\hline Morrotes & $>15 \%$ & $<100 \mathrm{~m}$ \\
\hline Morros & $>15 \%$ & De $100 \mathrm{~m}$ a $300 \mathrm{~m}$ \\
\hline Montanhoso e/ou Escarpado & $>15 \%$ & $>300 \mathrm{~m}$
\end{tabular}

Fonte: IPT (1981)

Para o mapeamento de sistemas de relevo para a BHRSJ foram feitas pequenas adaptações na metodologia aplicada pelo IPT (1981) no estado de São Paulo. Para a bacia em estudo, foi desconsiderada a classe de Morros com Vertentes Suavizadas, já que esta classe foi registrada em apenas $0,7 \%$ da área mapeada, e ainda assim de forma muito dispersa. Além disso, foi criada a classe de Relevo Plano ou Suavemente Colinoso, que são as áreas onde o valor de declividade não ultrapassa o percentual de $5 \%$ e a amplitude do relevo é sempre inferior a 40m. A classe de Relevo Colinoso passou a ser as áreas onde a declividade das encostas está entre $5 \%$ e $15 \%$ e a amplitude do relevo sempre está abaixo de 40m (tab. 2).

Tabela 2: Classes de Sistemas de Relevo para a BHRSJ

\begin{tabular}{l|c|c}
\multicolumn{1}{c|}{ Sistemas de Relevo } & Declividade & Amplitude do Relevo \\
\hline Relevo Plano ou Suavemente Colinoso & $0 \%$ a $5 \%$ & $<40 \mathrm{~m}$ \\
\hline Colinoso & $5 \%$ a $15 \%$ & $<40 \mathrm{~m}$ \\
\hline Morrotes & $>15 \%$ & De 40 a $100 \mathrm{~m}$ \\
\hline Morros & $>15 \%$ & De $100 \mathrm{~m}$ a $300 \mathrm{~m}$ \\
\hline Montanhoso & $>15 \%$ & $>300 \mathrm{~m}$ \\
\hline
\end{tabular}

Fonte: Adaptado do IPT (1981)

O produto gerado a partir do cruzamento dos mapas temáticos de amplitude do relevo e declividade das encostas, fatiados pelas classes descritas acima (tab. 2), deu origem ao mapa de Domínios Geomorfológicos da BHRSJ. Foram aplicados processos de generalização, como filtro de moda $(5 \times 5)$ e eliminação de áreas inferiores a 2 hectares, para supressão de ruídos surgidos após a combinação dos temas envolvidos. Por fim, todo o mapa passou por processo de edição manual com o auxílio de uma imagem Spot 5 do ano de 2005, com resolução espacial de 2,5 x 2,5 m, cedida pelo laboratório de Geografia Física (LAGEF) do Departamento de Geografia da UFF (fig. 7). 


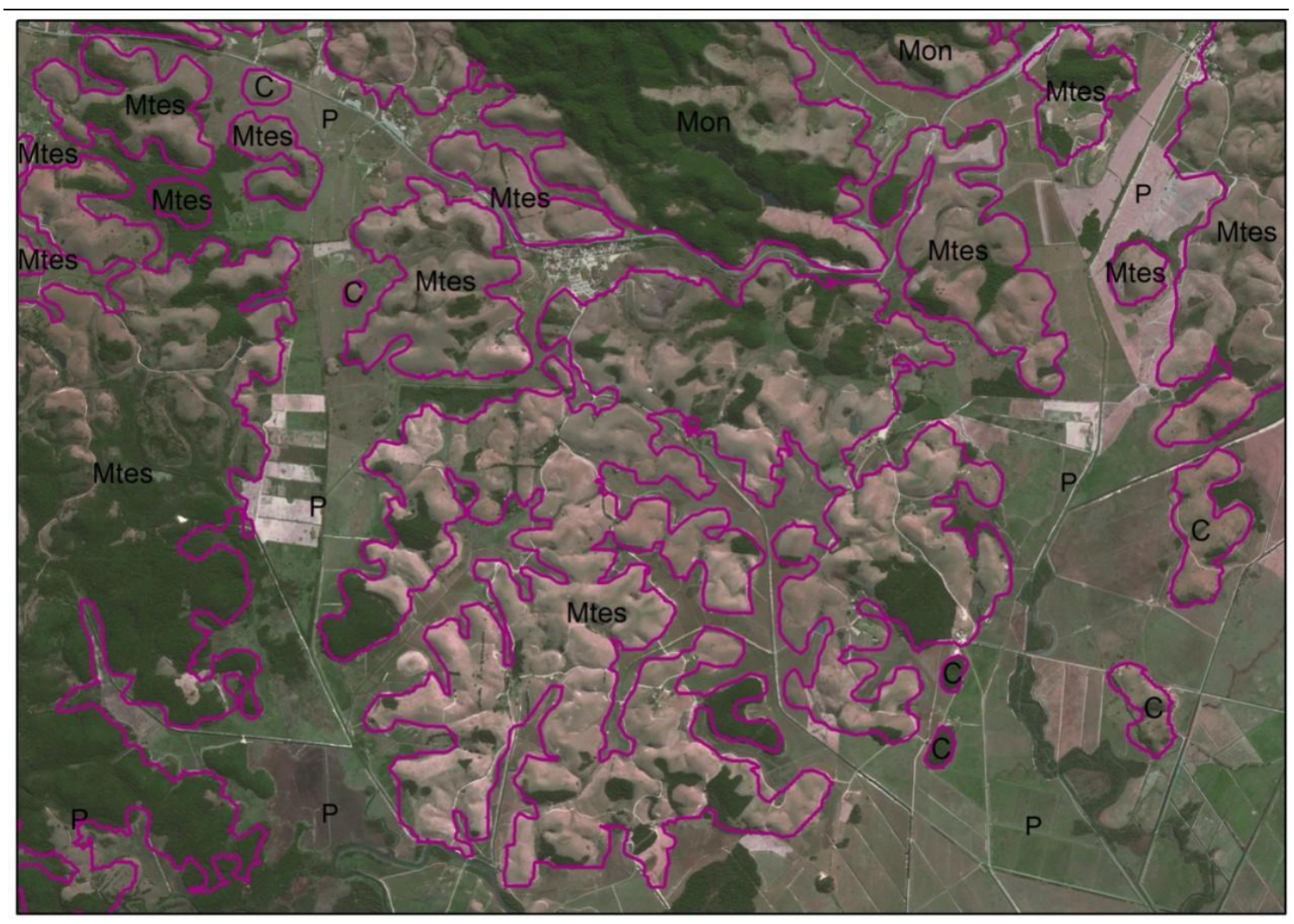

P - Relevo Plano

C - Relevo Colinoso

Mor - Relevo de Morros
Mtes - Morrotes

Mon - Relevo de Montanhas

Figura 7. Edição do Mapa de Sistemas de Relevo para a BHRSJ

\section{RESULTADOS}

Após a edição final, o Mapa de Sistemas de Relevo mostrou-se bem compatível com a realidade da BHRSJ (fig. 8). O resultado final aponta que o Relevo Plano ou Suavemente Colinoso predomina na Bacia do Rio São João, correspondendo a $31,14 \%$ da área total. Em seguida temos o relevo Montanhoso, que é o segundo de maior presença na bacia $(30,46 \%)$, sendo representado principalmente: pelo Morro de São João, localizado próximo a foz do Rio São João; pelos Maciços da Serra do Mar, presentes na Porção Norte e Noroeste da Bacia e; por Maciços Costeiros, localizados na porção Sudoeste da BHRSJ (quadro 1).

O relevo colinoso (fig. 9) está presente principalmente na porção sul e sudeste da BHRSJ, correspondendo a $20,03 \%$ de toda a área mapeada. Os morrotes representam
8,96\% de toda a área, seguidos dos morros, que contabilizam $7,73 \%$ da bacia. Os corpos d'água, representados principalmente pela Represa de Juturnaíba, cobrem $1,68 \%$ da área total mapeada.

A avaliação do mapa geomorfológico a partir dos trabalhos de campo realizados na BHRSJ comprovou que a metodologia elaborada pelo IPT (1981) alcança ótimos resultados para representação do relevo, desde que seja adaptada para atender às particularidades de cada área. A construção de perfis topográficos a partir do MDE ASTER (fig. 10) serviu para ajustar os resultados preliminares encontrados. As edições necessárias, efetuadas com o auxílio da imagem SPOT 5, serviram para refinar o contorno dos polígonos e para definir os contornos de algumas feições (ex: linha de costa).

Quadro 1: Percentual de área para cada classe de Relevo na BHRSJ. 


\begin{tabular}{|l|r|}
\hline \multicolumn{1}{|c|}{ Classe de Relevo } & \multicolumn{1}{c|}{ \% de Área } \\
\hline Corpos d'água & 1,68 \\
\hline Relevo Plano ou Suavemente Colinoso & 31,14 \\
\hline Relevo Colinoso & 20,03 \\
\hline Relevo de Morrotes & 8,96 \\
\hline Relevo de Morros & 7,73 \\
\hline Relevo Montanhoso & 30,46 \\
\hline
\end{tabular}

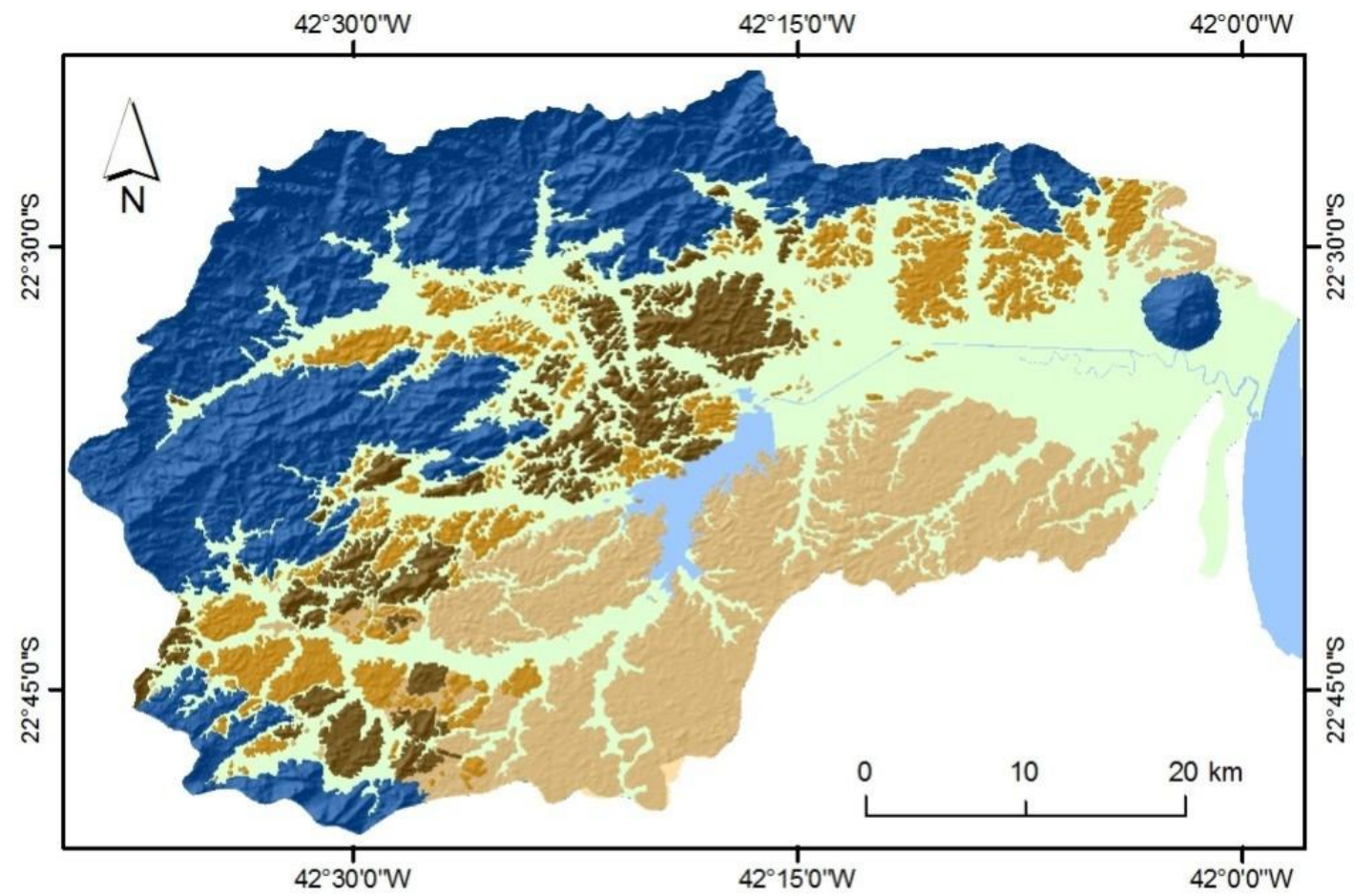

Domínios Geomorfológicos

Dominio Montanhoso

Dominio de Morrotes

Dominios Colinosos

Dominio de Morros

Dominio de Planicies

Corpos d'água

Figura 8. Domínios Geomorfológicos da BHRSJ. Projeção Cilíndrica Equiretângular. SIRGAS 2000.

\section{CONCLUSÕES}

Os levantamentos e análises realizados neste capítulo evidenciam o grande potencial que os produtos de sensoriamento remoto e as ferramentas de análise espacial presentes nos SIGs têm para os estudos voltados para a caracterização e espacialização dos componentes e estruturas da paisagem. É importante ainda salientar que todos dados utilizados nestas análises foram adquiridos gratuitamente, aumentando a viabilidade do uso destes produtos em pesquisas científicas. 


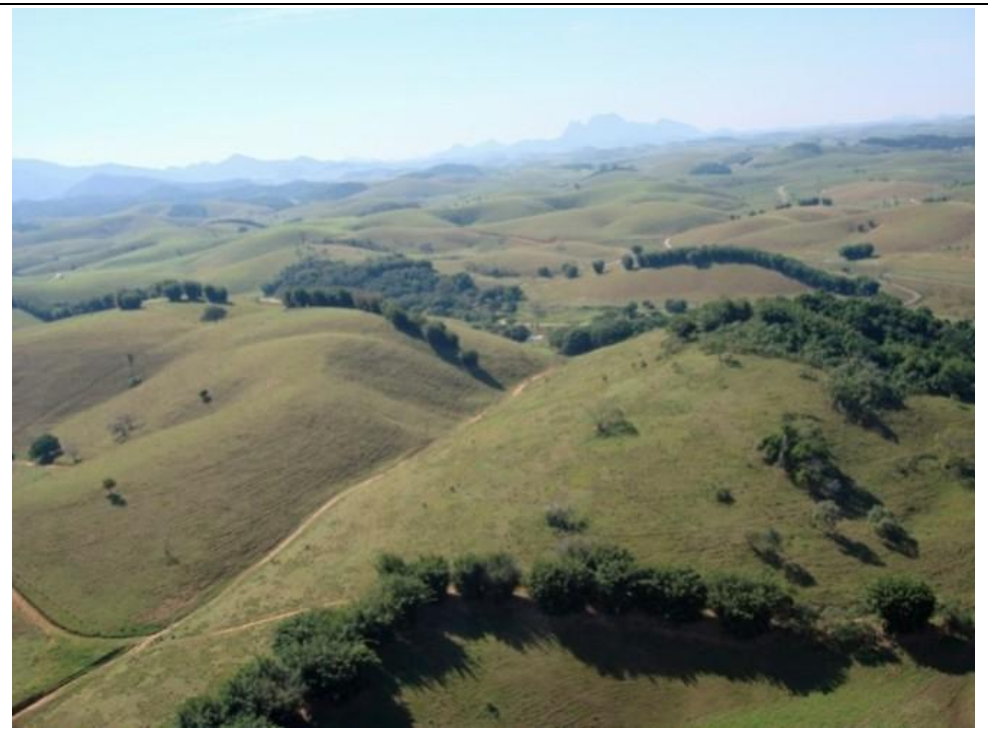

Figura 9. Relevo de Colinas na BHRSJ
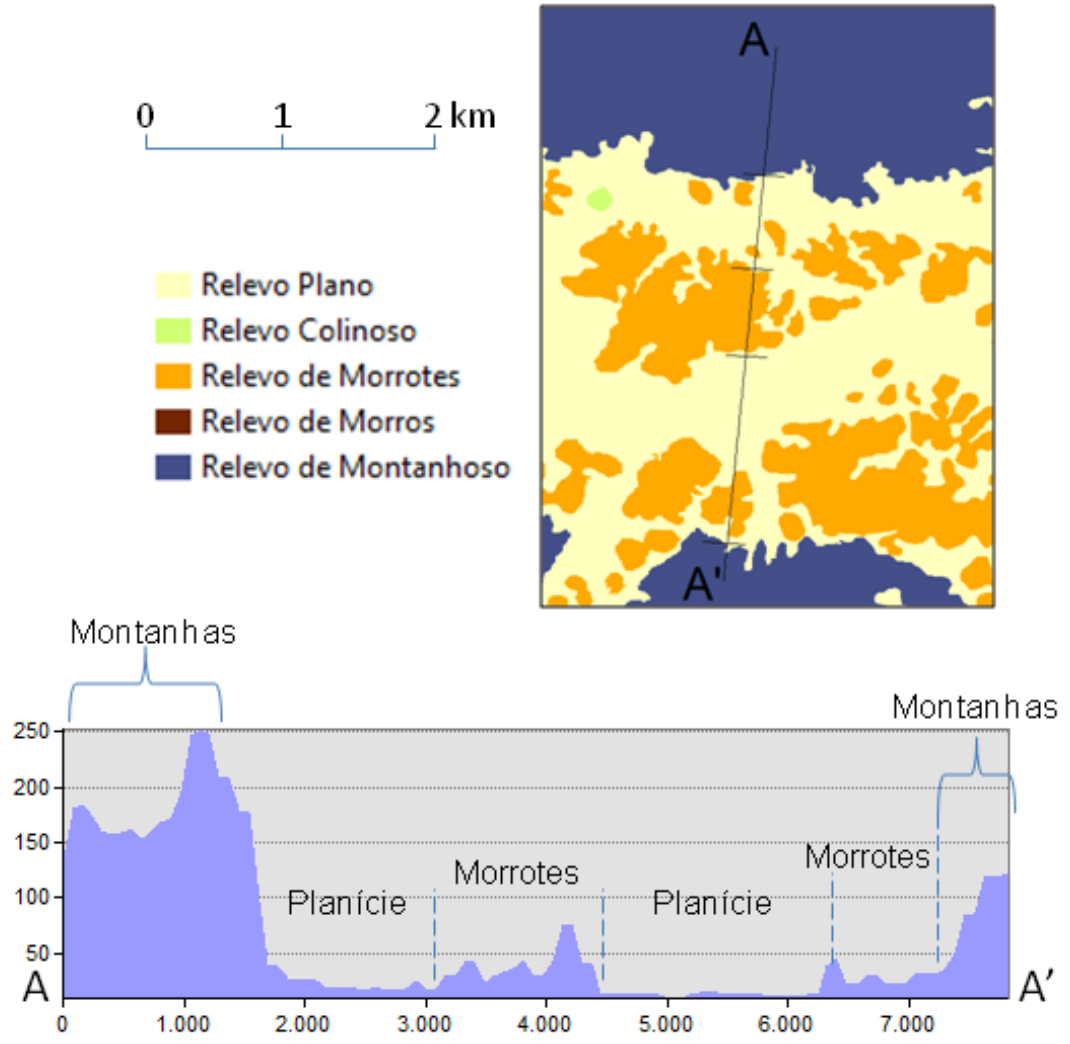

Figura 9. Perfil Topográfico na BHRSJ.

A extração de informações através da manipulação do MDE ASTER apresentou ótimas respostas, o que resultou na geração dos mapas de declividade, bacias de drenagem, amplitude do relevo, radiação solar e forma do terreno bem compatíveis com as observações feitas em trabalhos de campo. A partir dos trabalhos de campo também pudemos constatar que o MDE ASTER apresentou resultados satisfatórios em termos de representação temática pois identificou acertadamente as feições desejadas para o mapeamento, atendendo com isso as pretensões de escala (1:100.000). 
Após a edição final, o Mapa de Sistemas de Relevo mostrou-se compatível com a realidade da BHRSJ, comprovando que as adaptações da metodologia elaborada pelo IPT (1981) e sua aplicação na BHRSJ apresentaram resultados muito satisfatórios. As edições necessárias, efetuadas com o auxílio da imagem SPOT 5 , serviram para refinar o contorno dos polígonos e para definir os contornos de algumas feições (ex: linha de costa).

\section{REFERÊNCIAS BIBLIOGRÁFICAS}

BARROS, R. S. Avaliação da Altimetria de Modelos Digitais de Elevação Obtidos a Partir de Sensores Orbitais [Rio de Janeiro], 2006 XIX, 172p.(IGEO/UFRJ), D.Sc., Geografia, 2006 Tese - Universidade Federal do Rio de Janeiro, IGEO. 2006.

CILSJ - Consórcio Intermunicipal Lagos São João. Consórcio Intermunicipal para Gestão Ambiental das Bacias da Região dos Lagos, do Rio São João e Zona Costeira. Disponível em http://www.lagossaojoao.org .br/. Consultado em Janeiro de 2007.

FLORENZANO, T. G. Geomorfologia: conceitos e tecnologias atuais. São Paulo, Oficina de Textos, 2008.

FLORENZANO, T. G.; CSORDAS, S. M. Mapa geomorfológico da Região do Médio Vale do Paraíba e Litoral Norte do Estado de São Paulo. São José dos Campos: INPE, 1993.

GUERRA, A. J. T.; GUERRA, A. J. T. Novo Dicionário GeológicoGeomorfológico. Rio de Janeiro: Bertrand Brasil, 1997.

IPT - Instituto de Pesquisas Tecnológicas. Mapa geomorfológico do estado de São Paulo. São Paulo, 1981.
PIRES NETO, A. G. As abordagens sintético-histórica e analítico-dinâmica: uma proposição metodológica para a geomorfologia. Tese (Doutorado em Geografia Física) - FFLCH-USP. São Paulo, 1992. 